\title{
ESTABILIDAD E IMPORTANCIA POLITTICA DE LOS MINISTROS DE ESTADO. EL CASO DEL MINISTRO DE HACIENDA (1925-1973)
}

\author{
Sergi() CARRasco Delgado \\ Profesor de Derecho Constitucional e \\ Historia Constitucional de Chile \\ Facultad de Ciencias Jurídicas y Sociales \\ Universidad de Concepción
}

\section{DISPOSICIONES CONSTITUCIONALES Y LEGALES SOBRE LOS MINISTROS}

1.

Ya desde los primeros textos constitucionales chilenos se fijó el número y, en ocasiones, las funciones de los ministros.

Así se dispuso en los siguientes:

- Reglamento Constitucional Provisorio de 1812, artículo 14: "Para el despacho de los negocios habrá dos Secretarios, el uno para los negocios del reino, y el otro para las correspondencias de fuera".

- Reglamento para el Gobierno Provisorio de 1814, artículo 10: "...E1 Excmo. señor Director despachará con sus tres Secretarios de Gobierno, Hacienda y Guerra, elegidos en Junta de Corporaciones".

- Proyecto de Constitución Provisoria para el Estado de Chile de 1818, Título IV, Cap. I, artículo 10: "Es privativo del Supremo Poder Ejecutivo el nombramiento de los Secretarios de Estado, de Gobierno, Hacienda y Guerra, quien será responsable del nombramiento como éstos de sus respectivos empleos".

- Constitución Política del Estado de Chile de 1822, artículo 124: "Habrá tres Ministros Secretarios de Estado para el despacho de los negocios, de Gobierno y Relaciones Exteriores, de Hacienda, de Guerra y Marina".

- Reglamento Orgánico Provisional de 1823, artículo 12: "La Junta Gubernativa y sus Ministros quedan sujetos a la residencia, que le tomará el Tribunal que nombrase el Congreso Nacional".

- Reglamento Orgánico y Acta de Unión del Pueblo de Chile de 1823, artículo 6": "El Jefe de Estado es inviolable en todo el tiempo que debe 
ejercer sus funciones. Los Ministros son responsables, y pueden ser acusados o denunciados en cualquiera época".

- Constitución Política del Estado de Chile de 1823, artículo 21: "Habrá por ahora tres Ministros Secretarios de Estado para el Despacho Directorial". Además de los artículos 22 a 26, en el artículo 27 se dispone: "Los negocios y régimen interior de cada Departamento se fijarán por un reglamento, que formará el Gobierno y sancionará el Senado".

- Constitución Política de la República de Chile de 1828, artículo 86: "Habrá tres Ministros Secretarios de Estado para el Despacho. Cada uno de ellos será responsable de los decretos que firme, y todos de los que firmaren en común".

Además, artículos 87 a 89.

- Constitución de la República Chilena de 1833, artículo 84: "El número de los Ministros y sus respectivos Departamentos serán determinados por la ley". Además, artículos 85 a 101 (reformados en 1874).

- Constitución Política de la República de Chile de 1925, artículo 73: "El número de los Ministros y sus respectivos departamentos serán determinados por la ley". Además, artículos 73 a 78.

- Constitución Política de la República de Chile de 1980, artículo 33: "Los Ministros de Estado son los colaboradores directos e inmediatos del Presidente de la República en el gobierno y administración del Estado. La ley determinará el número y organización de los Ministerios, como también el orden de precedencia de los Ministros titulares...". Además, artículos 34 a 37.

2.

Durante el período correspondiente a la Constitución Política de 1833 los ministros fueron inicialmente 6 y posteriormente 9.

Durante el período de la Constitución Política de 1925 los ministros fueron inicialmente 9 y posteriormente 14 .

Durante la Constitución Política de 1980 los ministros han sido 18 más 3 cargos con rango de ministro.

3.

El orden de precedencia legal de los Ministros de Estado se estableció en el Decreto con Fuerza de Ley № 3.612, de 6 de agosto de 1930 y en el Decreto con Fuerza de Ley № 5.802, de 21 de octubre de 1942, del Ministerio del Interior. Éste faculta al Presidente de la República para que al dictar el decreto de nombramiento de un Ministro disponga que ocupará el primer lugar en el orden de precedencia legal para los efectos de su subrogación, situación en la cual el Ministro del Interior pasaría a ocupar el segundo lugar en el orden de precedencia. 


\section{ANTECEDENTES HISTÓRICOS}

4.

Durante el período propiamente seudoparlamentario (18911924) se llegó al extremo en el empleo de prácticas políticas, ya conocidas antes, como la interpelación y la censura de los ministros.

Con ello, lo que en el fondo se quería era subordinar el Gobierno, Presidente de la República, al Congreso.

5.

La neutralidad política y la disminución del rol del Presidente de la República se logran durante este período.

Con las excepciones, parcialmente, del presidente Pedro Montt M. (1906-1910) y, totalmente, del presidente Arturo Alessandri P. (1920-1925), los gobernantes ceden o se acomodan ante el sistema instaurado, ya sin reservas, desde 1891 . Pero que venía de antes ${ }^{1}$.

La importancia política debió trasladarse a los Ministros; sin embargo, ello tampoco ocurrió. Seguramente por la compatibilidad de los cargos de ministros con los de miembros del Congreso y, además, porque la llave de la Presidencia la tenían, hasta 1920, los "manipuladores políticos" o "los no peligro para nadie" y no los líderes o verdaderos conductores.

6.

La Constitución Política de 1925 fue dictada para corregir tales defectos, restituyendo un rol de importancia política para el Presidente de la República y haciendo a los ministros de su exclusiva confianza (artículo 72 № 5 de la C.P.), volviendo en éstos al texto original de la Constitución Política de 1833 (artículo 82 № 6 de la C.P.).

\section{MEDIDAS ADOPTADAS PARA ESTABLEGER EL RÉGIMEN POLÍTICO-CONSTITUCIONAL DESDE 1925. LA ESTABILIDAD MINISTERIAL}

7.

Ya relativamente a la vigencia efectiva de la Constitución Política del Estado de 1925, y además del gran tema de obtener la normalidad en materia de orden público, fue también básico lo correspondiente a concretar

${ }^{1}$ Ver Heise G., Julio, Historia de Chile. El Periodo Parlamentario. 1861-1925. 
el propósito de hacer posible el régimen presidencial, definiendo el campo propio de los poderes del Estado.

También fue un propósito difícil de cumplir.

Si sólo se considera el período 1925-1932, los cambios principales de Ministerios fueron los siguientes:
a) Junta de Gobierno (1925)
b) Arturo Alessandri P. (1925)
c) Luis Barros B. (1925)
d) Emilio Figueroa L. (1925-1927)
e) Carlos Ibáñez del C. (1927-1931)
f) Pedro Opazo L. (1931)
g) Juan Esteban Montero (1931)
h) Manuel Trucco F. (1931)
i) Juan Esteban Montero (1931-1932)
j) República Socialista (1932)
2
k) Bartolomé Blanche E. (1932)
l) Abraham Oyanedel U. (1932)
Total

O sea, en el período de los primeros 7 años 3 meses desde que fue promulgada la Constitución Política de 1925 hubo 27 cambios principales de ministerios.

Uno cada 3 meses, algunos de mínima duración.

El Ministro del Interior de mayor duración fue Guillermo Edwards Matte, desde el 5 de junio de 1928 al 24 de agosto de 1929 (1 año dos meses); el de Guerra de mayor duración fue el General Bartolomé Blanche E., desde el 21 de junio de 1927 al 26 de julio de 1931 (4 años un mes), y el de Hacienda de mayor duración fue Pablo Ramírez, desde el 9 de febrero de 1927 al 24 de agosto de 1929 (2 años 2 meses). Todos durante el gobierno del presidente Carlos Ibáñez, quien duró 4 años en sus funciones como tal (más de la mitad del período presidencial).

8. Durante el gobierno de Arturo Alessandri (1932-1938) se logró una relativa estabilidad ministerial.

\footnotetext{
${ }^{2}$ Los datos se remiten a los cambios de ministros del Interior.
} 
Considerando que los Ministerios eran 10, hubo 6 cambios de Ministro del Interior, en Relaciones Exteriores sólo 3 (uno de ellos, Miguel Cruchaga T. se desempeñó durante más de 4 años); un solo Ministro Titular (Emilio Bello C.) en Defensa Nacional, y en Hacienda sólo dos, de ellos Gustavo Ross S.M. se desempeñó por más de 4 años y su sucesor, Francisco Garcés G. por el resto del período.

O sea, básicamente se logró concretar el propósito constitucional de hacer depender la estabilidad de los Ministros de la voluntad del Presidente de la República.

Ello no fue de ningún modo fácil y así, Arturo Alessandri tuvo serias y precisas dificultades con el Partido Radical, colectividad de gran importancia en la época ("a quien debia mi elección"3) y que, por "razones doctrinarias" requirió, en 1934, la renuncia del ministro Miguel Cruchaga Tocornal del Ministerio de Relaciones Exteriores, donde realizaba una gestión no discutida en cuanto a su valor.

Por otra parte, con matices y dificultades, más apoyado por la "opinión pública" que por los partidos políticos, se reconocerá o se sostendrá el rol de los Presidentes de la República definido en la Constitución.

Sin embargo, Arturo Alessandri reconoció una realidad de su gobierno al consignar: "El Presidente de la República, sobre las bases fundamentales del gobierno democrático, en el régimen presidencial como en el parlamentario, debe auscultar y seguir el ritmo de la opinión pública"4.

Es lo que lleva al historiador Bernardino Bravo a concluir: "Así pues, con la segunda presidencia de Alessandri comenzó en 1933 la época del presidente negociador que concluye cuarenta años después con Allende en 1973. Se trata de una restauración del gobierno de partido en una nueva forma. Ahora ya no son los dirigentes partidistas quienes determinan la orientación del gobierno, como en el régimen parlamentario. A ello concurren estos dirigentes y el presidente. La línea del gobierno se define mediante la negociación entre ellos"5.

9.

Deben, sí, tenerse presentes, entre otros, dos hechos o circunstancias sobre el curso posterior:

${ }^{3}$ Alessandri P., Arturo, Recuerdos de Gobiemo, tomo III, 48.

${ }^{4}$ Mensaje del Presidente de la República al inaugurar el período ordinario de sesiones del Congreso, 21 de mayo de 1936, 83.

${ }^{5}$ Bravo L., Bernardino, El Presidente en la Historia de Chile, 74. 
a) Que como "opinión pública" seguía considerándose, principalmente, la de quienes desempeñaban una función pública, principalmente el Presidente de la República y los Partidos Políticos, lo cual comenzaría a variar ${ }^{6}$.

b) Que los problemas económico-sociales y no los doctrinarios comenzarían a gravitar ya decisivamente como preocupaciones colectivas en términos tales de influir, en tal forma, en los propósitos y decisiones populares.

De aquí que sería creciente, como luego se apreciará, la importancia del Ministro de Hacienda quien pasaría a sustituir, en su concepto público, al Ministro del Interior, antes el principal.

El caso, ya entre 1932 y 1937, del Ministro de Hacienda, Gustavo Ross Santa María fue decidor de esta situación.

10.

Como se ha señalado, en el artículo 72 de la Constitución Política de 1925 se dispuso: "Son atribuciones especiales del presidente": ...№ 5 Nombrar a su voluntad a los Ministros de Estado...", norma similar a la del artículo 82 № 6 de la Constitución Política de 1833: "Son atribuciones especiales del Presidente: ...6 $6^{\mathrm{a}}$ Nombrar y remover a su voluntad a los Ministros del Despacho...".

Hay aquí una clara manifestación de la diferencia que suele plantearse entre una norma constitucional y la aplicación de ésta.

Porque es un hecho muy claro que, durante una parte importante del período regido por la Constitución de 1833 los Ministros no pudieron ser nombrados ni removidos "a su voluntad" por el Presidente de la República sino que el Congreso y, por consiguiente, los partidos políticos representados en éste, por medio de las censuras a los gabinetes y por la constitución de mayorías parlamentarias tuvieron la facultad de intervenir "decisivamente" en la designación y remoción de los Ministros. Y como esta facultad se ejerció, además, sin moderación, se generó el problema conocido como de "la rotativa ministerial".

En la materia, esto es lo que quiso corregir principalmente, la norma del artículo 72 № 5 de la Constitución Política de 1925, casi igual a la del texto de 1833; tenía entonces un alcance muy preciso: que los Ministros de Estado fueran de la designación y confianza exclusiva de los Presidentes, como expresión del régimen presidencial y como manera de posibilitar un gobierno eficiente poniendo término a "la rotativa ministerial".

${ }^{6}$ Los principales, a la época, eran los partidos Radical, Conservador, Liberal y Democrático y otros sectores afines que reunían casi el $80 \%$ de la votación nacional. 

bios principales de ministerios -del Interior y de Hacienda-, fue la siguiente:

\section{Noy prom. en Int. $\quad \mathrm{N}^{\mathrm{a}}$ y prom. en $\mathrm{Hac}$.}
a) Período once gobiernos
25-3 ms.
20-4 ms.
(1925-1932)
b) Gobierno Arturo Alessandri
6-1 año
2-3 años
(1932-1938)
c) Gobierno Pedro Aguirre Cerda
$7-5 \mathrm{~ms}$.
$4-9 \mathrm{~ms}$.
(1938-1941)
d) Gobierno Juan Antonio Ríos
9-6 ms.
6-9 ms.
(1942-1946)
e) Gobierno Gabriel González
$7-10 \mathrm{~ms}$
6-1 año
(1946-1952)
f) Gobierno Carlos Ibáñez
$14-5 \mathrm{~ms}$
9-8 ms.
(1952-1958)
g) Gobierno Jorge Alessandri
2-3 años
3-2 años
(1958-1964)
h) Gobierno Eduardo Frei
3-2 años
3-2 años
(1964-1970)
i) Gobierno Salvador Allende
8-4 ms.
$6-6 \mathrm{~ms}$.
(1970-1973)
Total en el período
81-7 ms.
59-10 ms.
(1925-1973)
Considerando sólo 1932-1973
56-9 ms.
39-13 ms.

Estas cifras, remitidas sí al período de efectiva vigencia de la Constitución Política de 1925, o sea, desde fines del año 1932, permiten extraer varias conclusiones:

Primero. Que la estabilidad de los ministros del sector "político" fue inferior a la de los ministros del sector económico, lo que indicaría una mayor preocupación por estas materias.

Segundo. Que relativamente a los cambios ministeriales del sector "político" los gobiernos con mayor estabilidad fueron, en este orden, los de los presidentes: 
Jorge Alessandri R. (promedio 3 años),

Eduardo Frei M. (promedio 2 años), y

Arturo Alessandri P. (promedio 1 año).

Los gobiernos con menor estabilidad ministerial fueron, en este orden, los de los Presidentes

Salvador Allende G. (promedio 4 meses),

Carlos Ibáñez del C. (promedio 5 meses) y

Pedro Aguirre C. (promedio 5 meses).

El Ministro del Interior de mayor duración fue Sótero del Río Gundián (19 de enero de 1959 a 3 de noviembre de 1964), en el gobierno del Presidente Jorge Alessandri R.

Tercero. Que relativamente a los cambios ministeriales del sector "económico" los gobiernos con mayor estabilidad fueron, en este orden, los de los Presidentes:

Arturo Alessandri P. (promedio 3 años),

Jorge Alessandri R. (promedio 3 años) y

Eduardo Frei M. (promedio 3 años).

Los gobiernos con menor estabilidad ministerial fueron, en este orden, los de los Presidentes

Salvador Allende G. (promedio 6 meses)

Carlos Ibáñez del C. (promedio 9 meses) y

Juan Antonio Ríos M. (promedio 9 meses).

El Ministro de Hacienda de mayor duración fue Gustavo Ross Santa María (24 de diciembre de 1932 a 28 de marzo de 1937), en el gobierno del Presidente Arturo Alessandri P.?

Cuarto. Que, en consecuencia, si bien durante el período de efectiva vigencia o aplicación de la Constitución Política de 1925 hubo una mayor estabilidad ministerial que en el período seudoparlamentario (18911925), puede concluirse que ésta no es -en promedio- mayor sino apenas en

${ }^{7}$ En el período de vigencia de la Constitución Política de 1925 fueron ministros durante prácticamente toda una administración (de seis años) Emilio Bello Codesido (en Defensa, gobierno de Arturo Alessandri P.), Julio Phillipi Izquierdo y Enrique Ortúzar Escobar (ambos en varios ministerios, gobierno de Jorge Alessandri R.) y Gabriel Valdés Subercaseaux (en Relaciones Exteriores, gobierno de Eduardo Frei M.). El general Guillermo Barrios Tirado desempeñó el cargo de Ministro de Defensa por más de cinco años (1947-1952, durante el gobierno de Gabriel González V.). 
el doble de dicho período; así, cambios promedios en el Ministerio del Interior cada 9 meses y en el de Hacienda cada 1 año 1 mes.

Aún más, como los promedios no son sino eso ("punto en que una cosa se divide por mitad o casi por la mitad"8), del estudio de los 8 gobiernos que tuvo Chile durante el período de 41 años (1932-1973), en que se aplica -aun cuando con diferencias- la Constitución Política de 1925, sólo en 3-que en conjunto duran 18 años- hubo real y casi permanente estabilidad ministerial: durante los gobiemos de los presidentes Arturo Alessandri Palma (1932-1938), Jorge Alessandri R. (1958-1964) y Eduardo Frei M. (1964-1970).

En los otros cinco gobiernos, sin perjuicio de algunos lapsos de tiempo o en algunas carteras, la regla general fue la inestabilidad.

12.

Las razones principales de la estabilidad ministerial, fueron:

a) En el gobierno de Arturo Alessandri P. (1932-1938), la disposición de éste a establecer la plena vigencia de la Constitución, la defensa que el Presidente de la República hizo de sus prerrogativas como Jefe del Gobierno, el disponer -en la mayor parte de su administración- de apoyo partidario mayoritario en el Congreso y a la comprensión que -en materia económica, atendida la crisis producida- la estabilidad era fundamental.

b) En el gobierno de Jorge Alessandri R. (1958-1964), la constancia del Presidente en cuanto a gobernar con ministros independientes, salvo el lapso de tiempo del 26 de agosto de 1961 al 14 de septiembre de 1963 en el cual ingresaron al gobierno como tales los Partidos Radical, Conservador y Liberal, pero en el que se mantuvieron los ministros independientes más destacados, el respaldo -aun cuando con dificultades de los partidos políticos mayoritarios-y el creciente apoyo de Jorge Alessandri en la también creciente opinión pública, que le permitió situar al Presidente por sobre las colectividades políticas.

c) En el gobierno de Eduardo Frei M. (1964-1970), principalmente la circunstancia de gobernar con un solo partido, el Demócrata Cristiano, que en 1965 había elegido más de la mitad de los diputados (82 de 147) y casi un tercio del Senado (13 de 45) a lo que deben agregarse por lo menos 4 senadores que también apoyaban al gobierno. $\mathrm{Y}$ a las diferencias extremas entre los dos grandes sectores políticos opositores a su gobierno.

La circunstancia de lograr la estabilidad ministerial no excluyó que en los tres gobiemos precedentes existieran dificultades políticas de importancia, que obligan a ciertos distingos, pero, en cuanto a la finalidad

${ }^{8}$ Diccionario de la Real Academia Española de la Lengua. 
constitucional descrita al inicio, puede concluirse que fue, en general, cumplida.

13.

Ahora, como principales razones de la inestabilidad ministerial en los otros cinco gobiernos del período, pueden estimarse los siguientes:

a) En el gobierno del presidente Pedro Aguirre C. (19381941), las dificultades del gobernante con el Partido Radical, al cual pertenecía y que llegó incluso a retirarse del gobierno y a expulsar algunos ministros ${ }^{9}$ y también a la heterogeneidad de la combinación política gobernante (el Frente Popular: constituido en 1936, se disolvió en 1941).

Habiéndose nombrado, en 1940, un nuevo gabinete formado únicamente por ministros pertenecientes al Partido Radical, la Junta Central de éste planteó al Presidente el cambio de tales ministros lo que motivó a Aguirre a redactar su renuncia dirigida al Presidente del Partido Radical ${ }^{10}$.

"El punto neurálgico del conflicto entre el Presidente y la Junta Central Radical fue el artículo 72 № 5 de la Constitución Política. Durante esta dificultad, encontré una vez en su escritorio a don Pedro -recuerda el político radical Alberto Cabero- quien me dijo con hondo pesar: "Es muy dificil gobernar entre una derecha intransigente y una Junta Central Radical que tiene la pretensión de dirigir al país"... Indudablemente la mayoría de la Junta Central deseaba que el Presidente abdicara la facultad que le daba la Constitución en favor de una asamblea política, tumultaria y cambiante como era la Junta"ll.

b) En el gobierno del presidente Juan Antonio Ríos M. (19421946), también actuaron como factores de la inestabilidad ministerial los conflictos del Presidente de la República con el Partido Radical y con el

${ }^{9}$ En una comida que se dio a Pedro Aguirre, antes de asumir el Gobierno, habló Gabriel González Videla, Presidente del Partido Radical, y dijo que el Presidente de la República debía ser "un funcionario del Partido, a sus órdenes". Don Pedro Aguirre, sin esperar ser anunciado, habló y dijo que lo expresado "por mi querido amigo Gabriel González" no era su criterio y "olvidese señor González que yo vaya a desempeñarme como funcionario del partido". Entrevista del profesor investigador con Raúl Rettig Guissen, Santiago, 27 de abril de 1994.

${ }^{10}$ Texto completo de ésta en Cabero, Alberto, Recuerdos de don Pedro Aguirre Cerda, 249-252. "Por ventura, el borrador que conocí y que ahora reproduzco no alcanzó a escribirse a máquina y menos se realizó su envío...", Cabero, cit., 49.

${ }^{11}$ Cabero, Recuerdos, cit, 255 . También narración de algunos hechos en Olavarría B., Arturo, Chile entre dos Alessandri, 417-419, 503-505, 574-577. 
Partido Socialista, lo que llevó incluso al nombramiento como Ministros de algunos miembros de las Fuerzas Armadas. "El Presidente no admite menoscabo en su autoridad especialmente en funciones que le son propias sin que se altere la unidad de acción de su gobierno"12. Y también se debió a la circunstancia que, hacia 1945, los partidos políticos de gobierno fueron derrotados en las elecciones generales de parlamentarios.

c) En el gobierno del presidente Gabriel González Videla (1946-1952), si bien hubo una etapa (1947-1950) en que los cargos de Ministros del Interior y de Hacienda fueron desempeñados sólo por dos y una persona, respectivamente, tanto durante el primer año de este gobierno como en los dos últimos se produjo una importante rotativa.

La etapa de mayor estabilidad durante su gobierno se debió, principalmente, a la formación de un "Gabinete de Administración" (agosto 1947-julio 1948) ${ }^{13}$, que se prolongó por once meses y que fue seguido por el "Gabinete de Concentración Nacional" (julio 1948-febrero 1950), correspondiente a la participación de los Partidos Radical, Conservador, Liberal, Democrático y Socialista, además de independientes.

Los cambios políticos de su primera etapa, principalmente la proscripción del Partido Comunista, y los posteriores a 1950 en que se apreciaba la disminución del Partido Radical ${ }^{14}$, determinaron nuevos cambios de ministros, si bien algo más alternados que los producidos durante los dos gobiernos anteriores.

d) El gobierno del presidente Carlos Ibáñez del C. (19521958) se caracterizó por un reiterado cambio de ministros. Ya se señalaron las cifras globales correspondientes a los Ministerios básicos del Interior y de Hacienda que, en su caso, fueron 14 y 9 , respectivamente. Pero, además, si se considera que los ministerios de la época fueron 12 ó 13, 86 personas distintas ocuparon tales cargos -algunos muy brevemente- en este período de seis años.

${ }^{12}$ Contestó Ríos a la directiva del Partido Socialista en junio de 1942. Citado por Cabero, 255-256.

${ }^{13}$ Sobre este Gabinete y sus circunstancias, ver González Videla, Gabriel, Memorias, tomo I, 598-600.

${ }^{14}$ En la elección presidencial de 1952, el candidato radical Pedro Enrique Alfonso Barrios, ex ministro de los gobiernos de los presidentes Aguirre y González sólo obtuvo 190.360 sufragios, casi el 20\% del total, terminando, así, con Gabriel González $\mathrm{V}$., el ciclo de los denominados "gobiernos radicales". 
Deben considerarse, para la comprensión de lo ocurrido durante esta administración, las circunstancias de la elección del Presidente Ibáñez, apoyado por sectores independientes, por una multiplicidad de pequeños movimientos y por sólo dos partidos medianamente organizados, el Partido Agrario Laborista y el Partido Socialista Popular ${ }^{15}$. También lo especial de su gobierno caracterizado por las variaciones políticas del mandatario y la tendencia a variar, sin mayores explicaciones, sus ministerios ${ }^{16}$.

e) Durante el gobierno del presidente Salvador Allende G. (1970-1973), que es el de mayor inestabilidad ministerial, sus causas pueden encontrarse en la naturaleza de la combinación política -de Unidad Popular-, en las discrepancias surgidas dentro de ésta, en la designación y renuncias de ministros pertenecientes a las Fuerzas Armadas, en el conflicto entre el Presidente de la República y la mayoría del Congreso, en las destituciones de ministros hechas por el Senado al acoger acusaciones constitucionales y en los graves hechos sociales desencadenados durante el período.

Ahora, esta rotativa ministerial no se derivó -como ocurrió durante el seudoparlamentarismo- de la existencia de mecanismos que posibilitaron la "censura" de los Gabinetes sino que, ahora, de otros procedimientos, como el "pase" o "la orden de retiro" que los partidos políticos aplicaban respecto de sus militantes, los cuales sólo excepcionalmente desconocían ${ }^{17}$.

Principalmente el Partido Radical, entre los años 1933-1963 empleó el mecanismo de la "orden de retiro" creándose, así, importantes conflictos en los gobiernos en que participó.

Pero aún sin considerar estos mecanismos, las colectividades políticas intervinieron en la facultad privativa de los Presidentes de nombrar Ministros, bien condicionando a ello su apoyo en el Congreso o la propia permanencia en el gobierno, imponiendo así ciertas tendencias ${ }^{18}$.

${ }^{15}$ Que se retiró del gobierno a fines de 1953.

${ }^{16}$ Ver en Olavarría B., Arturo, cit. tomo II, 291-297.

${ }^{17} \mathrm{X}$, en tal caso, eran expulsados de la colectividad a que pertenecían. Solamente el designado Ministro de Educación Pública, Francisco Cereceda Cisterna, antiguo y pasivo militante liberal no solicitó, en 1958, el "pase" para aceptar el cargo. Pero, hasta entonces, lo usual era que éste se pidiera.

${ }^{18} \mathrm{Si}$ bien fue excepcional en tal gobierno, se puede señalar la oposición de las directivas de los Partidos Liberal y Conservador a la designación de Jorge Prat Echaurren como Ministro del Trabajo en 1958 (gobierno Jorge Alessandri R.). Y, generalmente, la provisión de los cargos de Ministros en el gobierno del presidente Salvador Allende G., 
De manera que la norma del artículo 72 № 5 de la Constitución de 1925 sobre designación de los Ministros, considerada indispensable al elaborarse el texto fundamental, si bien cumplida en lo formal, sustancialmente no representó cabalmente el propósito expresado en la etapa de génesis de la Constitución Política del Estado de 1925.

14.

Complementando lo anterior, con referencia a los distintos gobiernos, las acusaciones constitucionales deducidas en contra de Ministros o ex Ministros de Estado, que fueron las con más significación política, tuvieron el resultado que a continuación se consigna:

\begin{tabular}{lccc}
\hline Gobierno & Presentadas & $\begin{array}{c}\text { Ha lugar C. } \\
\text { de Dip. }\end{array}$ & $\begin{array}{c}\text { Aprobadas en } \\
\text { Senado }\end{array}$ \\
\hline Junta 1925 & 4 & 0 & 0 \\
Carlos Ibáñez & 17 & 7 & 1 \\
Arturo Alessandri & 5 & 0 & 0 \\
Pedro Aguirre & 4 & 3 & 0 \\
Juan A. Ríos & 2 & 0 & 0 \\
Gabriel González & 6 & 0 & 0 \\
Carlos Ibáñez & 8 & 4 & 2 \\
Jorge Alessandri & 8 & 0 & 0 \\
Eduardo Frei & 8 & 3 & 7 \\
Salvador Allende & $\mathbf{1 4}$ & 9 & $\mathbf{1 0}$ \\
Totales & $\mathbf{7 6}$ & $\mathbf{2 6}$ & $\mathbf{( 1 3 , 1 6 \% )}$ \\
\end{tabular}

O sea, sólo respecto de un reducido porcentaje de las acusaciones constitucionales presentadas se declaró, por la Cámara de Diputados, haber lugar. Y un porcentaje mucho menor fue la de acusaciones en que se aprobó por el Senado, destituyéndose al funcionario acusado.

En cuanto a los Ministros de Estado, los más frecuentemente acusados fueron los de Interior y de Hacienda.

En el caso del gobierno del presidente Carlos Ibáñez del C. (1927-1931), al terminar éste se dedujeron diversas acusaciones, en varias

aplicándose -en la época- el sistema de intervenir directamente las directivas políticas en los nombramientos de ministros. 
juntamente algunos ministros, lo que indica un número mayor pero, en realidad, fue prácticamente una sola gran acusación con diversas tramitaciones.

El gobierno durante el cual hubo realmente más casos de acusaciones constitucionales y un número muy superior de destituciones fue el del presidente Salvador Allende G. (1970-1973); los ministros destituidos fueron siete, correspondiendo a la mitad de las acusaciones deducidas.

En los últimos años de vigencia de la Constitución Política de 1925 se comenzó a aplicar un sistema -sustancialmente inconstitucionalconocido como el de los "enroques de Ministros".

O sea, acusado y suspendido un ministro se le volvía a nombrar de inmediato como titular en otra cartera. Sistema empleado durante el gobierno del presidente Salvador Allende G., el 7 de enero de 1972, al designar a don José Tohá G. en Defensa Nacional, estando suspendido como Ministro del Interior.

Ya antes, el presidente Carlos Ibáñez del C., había nombrado con posterioridad a sus destituciones, en otras carteras, a los señores Arturo Zúñiga L. y Osvaldo Saint-Marie S.

$\mathrm{Si}$ bien las acusaciones constitucionales, especialmente las deducidas contra los Ministros de Estado contuvieron, en muchos casos, una crítica más general, extensiva al gobierno, y afectaron así la estabilidad de los ministros, la amplitud de las causales correspondientes -delito de traición, concusión, malversación de fondos públicos, soborno, infracción de la Constitución, atropellamiento de las leyes, por haberlas dejado sin ejecución y por haber comprometido gravemente la seguridad o el honor de la Nación- hizo habitualmente, a lo menos pertinentes, la interposición de las correspondientes acusaciones sin que se afectara el texto ni el espíritu de la Constitución Política de 1925.

\section{IMPORTANCIA POLÍTICA DE LOS MINISTROS. EL CASO DEL MINISTRO DE HACIENDA}

15. El crecimiento de la población electoral y, por consiguiente, de la opinión pública es un hecho de extraordinaria importancia respecto del rol político de los Ministros.

Al respecto, y señalando esta materia dividida en períodos de aproximadamente diez años, considerando las respectivas elecciones generales de parlamentarios, la situación fue la siguiente: 


\begin{tabular}{lccc}
\hline Año & Población & $\begin{array}{c}\text { Inscritos en } \\
\text { Registr. Elect. }\end{array}$ & $\begin{array}{c}\text { Porcentaje respecto } \\
\text { de la población }\end{array}$ \\
\hline 1925 & 4.073 .000 & 302.142 & $7,42 \%$ \\
1937 & 4.842 .000 & 495.648 & $10,24 \%$ \\
1945 & 5.541 .000 & 641.495 & $11,58 \%$ \\
1953 & 6.482 .000 & 1.100 .027 & $16,97 \%$ \\
1965 & 8.510 .000 & 2.920 .615 & $34,32 \%$ \\
1973 & 9.861 .000 & 4.509 .559 & $45,73 \%$ \\
\hline
\end{tabular}

Puede al respecto concluirse que la tendencia que se aprecia es, inicialmente, de una escasa variación llegando el electorado en los primeros veinte años desde la promulgación de la Constitución de 1925 a sólo algo más del $11 \%$ de la población total de Chile.

Después se aprecia un aumento en pocos años que se debe, principalmente, al sufragio femenino y sólo desde los años 1960 en adelante se va a concretar una clara y sostenida tendencia al aumento de la población electoral que llega así, hacia el término del período de vigencia de la Constitución Política de 1925, a constituir casi el $50 \%$ de la población.

Considerando el período comprendido entre los años 1925 y 1973, mientras la población total chilena aumentó un 142\%, el electorado (inscritos en los registros electorales) aumentó un $1.390 \%$ aproximadamente.

Este crecimiento considerable debió necesariamente expresar una mayor "opinión pública" que claramente fue manifestando sus verdaderas preocupaciones, cada vez más orientadas hacia los problemas económico-sociales.

Así, progresivamente, fue creciendo la importancia política del Ministro de Hacienda, o de los ministros del sector económico, no obstante las dificultades y eventual impopularidad en el ejercicio de tales funciones, en desmedro de la tradicional del Ministro del Interior.

16.

Es de importancia el estudio de las candidaturas y de las elecciones presidenciales del período.

${ }^{19}$ Datos de población estimada (en miles) en Chile, Series Estadísticas 1981, República de Chile, Ministerio de Economía, Fomento y Reconstrucción, Instituto Nacional de Estadísticas.

Datos de inscritos, proporcionados por la Dirección del Servicio Electoral, julio de 1995. 
Así, corresponde examinar el aspecto de la repetición constante de algunos mismos candidatos, en distintas elecciones. De treinta y seis candidaturas correspondientes a las once elecciones efectuadas entre los años 1925 y 1970, hubo diez en que se repiten las mismas personas, o sea, en 45 años sólo hubo, en realidad, veintiséis distintos candidatos a la Presidencia de la República.

Puede concluirse, al estudiar la generación de las candidaturas el influjo de ciertos "nombres" o "apellidos", casi verdaderas "marcas", que fueron garantía de apoyo electoral.

También que una gran mayoría de candidatos pertenecian a partidos políticos y sólo cuatro, de veintiséis, eran independientes. Sin embargo de estas cifras, que como todo dato debe ser correctamente empleado, no resulta sustancial y necesariamente un predominio partidista en la opinión.

Desde ya, si se considera que de los once Presidentes elegidos en el período, dos fueron independientes - Carlos Ibánez del C. (1927-1931; 1952-1958) y Jorge Alessandri R. (1958-1964).

En cuanto a los demás nueve, en su inmensa mayoría fueron personas o retiradas de la actividad partidista, como Emiliano Figueroa (19251927); de reducida vida partidista - como Juan Esteban Montero R. (19311932) ${ }^{20}$; no sujetos a disciplina partidista - como Arturo Alessandri P. (19321938); que fueron apoyados por combinaciones mucho más amplias que sus propios partidos - como Pedro Aguirre C. (1938-1941), Juan Antonio Ríos M. (1942-1946), Eduardo Frei M. (1964-1970) y Salrador Allende G. (1970-1973) - o que como personas excedieron importantemente los marcos partidistas, principalmente - Arturo Alessandri P. (1932-1938), Eduardo Frei M. (19641970) y también -aunque no necesariamente en la oportunidad en que fue elegido- Salvador Allende G. (1970-1973).

Los únicos presidentes que, en sus épocas, habrian sido elegidos por la fuerza propiamente partidista fueron Gabriel González V. (19461952), y en cierta medida Salvador Allende G. (1970-1973), pero sus dos elecciones tuvieron características muy especiales y en ambos casos los elegidos triunfaron por mayorías relativas reducidas y estrechas.

Más claro es aún si se tiene presente que las elecciones de los nueve Presidentes que tuvieron militancia partidista, en casi todas, salvo las de Gabriel González y de Salvador Allende, hubo una clara y mayoritaria mani-

${ }^{20}$ Ver Rettig G., Raúl, entrevista de abril de 1994: "Montero firmó los registros del Partido Radical, pero no hizo vida activa partidista". 
festación de voluntad popular en cuanto a razones determinantes, de preocupaciones por materias políticas y por temas económico-sociales, que excedieron los criterios puramente partidistas, según se señalará más adelante.

De todos los candidatos del período solo dieciséis pudieron. postular correspondiendo a una realidad auténtica, considerablemente representativa.

En realidad, los candidatos a Presidente de la República del período y preferentemente el criterio de los electores marcaron una tendencia más bien independiente o, a lo menos, suprapartidista respecto de los partidos políticos, en especial en el período 1952-1964, etapa en la cual fue determinante el crecimiento de la población electoral, el mayor interés general en la vida cívica y la creciente preocupación por los problemas económico-sociales.

17.

Es del caso señalar que - en cuanto a los candidatos presidenciales y a los elegidos- respecto de sus profesiones o actividades, se pueden considerar los siguientes datos:

\begin{tabular}{lrc}
\hline & Candidatos & Elegidos \\
\hline abogados & $13-50 \%$ & $6-60 \%$ \\
médicos & $3-12 \%$ & $1-10 \%$ \\
militares & $2-8 \%$ & $1-10 \%$ (2 veces) \\
profesores & $1-4 \%$ & $0-0 \%$ \\
ingenieros & $1-4 \%$ & $1-10 \%$ \\
obreros & $1-4 \%$ & $0-0 \%$ \\
otros & $5-8 \%$ & $1-10 \%$ \\
& & $(\mathbf{1 1 )}-\mathbf{1 0} 100 \%$
\end{tabular}

Sin embargo de estas cifras, en cuanto a los candidatos y los elegidos Presidente de la República, durante el período de vigencia de la Constitución Política de 1925 fue creciente la preocupación de la ciudadanía por los problemas económico-sociales y también, consiguientemente, fue creciente la importancia de los Ministros del sector económico-social, particularmente de Hacienda.

Así, en el período que va entre los años 1938 y 1964, postularon como candidatos a la Presidencia tres ex Ministros de Hacienda: Gustavo 
Ross Santa María (1932-1937) en 1938; Arturo Matte Larraín (1943) en 1952 y Jorge Alessandri Rodríguez (1947-1950), este último elegido en 1958.

También fue precandidato Jorge Prat Echaurren, en 1964, quien como Ministro de Hacienda del presidente Carlos Ibáñez se desempeñó, en su época, 1954, como jefe del gabinete.

Otros precandidatos vinculados a la actividad o conocimiento en materia económica fueron Óscar Schnake V., en 1942, ex ministro de Fomento; Francisco Cuevas Mackenna, en 1958, ex ministro de Hacienda; Guillermo del Pedregal H., en 1958; Alberto Baltra Cortés, en 1970, ex ministro de Economía y Comercio, y Felipe Herrera Lane, en 1970, ex ministro de Hacienda.

Considerando que la actividad de los Ministros de Hacienda fue siempre difícil e incomprendida en sus épocas, el hecho que sus titulares hayan crecientemente postulado indica una tendencia de la ciudadanía y de algunos sectores políticos muy decidora.

Si a ello se agrega el caso del presidente Pedro Aguirre, autor de las obras "El Problema Agrario" y "El Problema Industrial", el Plan Agrario del presidente Juan Antonio Ríos M., la actividad administrativa del presidente Carlos Ibáñez del C., los programas económicos de los gobiernos de los presidentes Eduardo Frei M. y Salvador Allende G. y, además, las circunstancias de cada elección, puede confirmarse la tendencia indicada.

18.

En cuanto a los ministerios que ocuparon los once Presidentes de la República del período, previamente a ser elegidos, pueden indicarse los siguientes datos:

Presidente de la República

Emiliano Figueroa A.

Carlos Ibáñez del C. Juan Esteban Montero R. Arturo Alessandri P.

Pedro Aguirre C. Juan Antonio Ríos M. Jorge Alessandri R. Eduardo Frei $M$. Salvador Allende G.
- Ministerios desempeñados

Justicia (1907)

Guerra (1925), Interior (1927)

Interior (1931)

Ind. y OO.PP (1898), Hacienda (1913),

Interior (1918)

Justicia (1918), Interior (1920; 1924)

Interior (1932)

Hacienda (1947)

OO.PP y Vías de Comunicación (1945)

Salubridad (1939) 


\section{CONCLUSIONES}

Primero. En cuanto al sistema de gobierno presidencial y la definición del campo propio de los poderes del Estado, durante 1925-1973 hubo una expresión -la estabilidad ministerial-cuyo alcance y consecuencias generales se han explicado, que fue difícil de obtener. Que desde fines de 1932 se logra, pero por períodos que no son la mayoría.

Si bien hubo mayor estabilidad que en el período seudoparlamentario, ésta no es -en promedio- mayor sino en el doble de tal etapa.

Segundo. En cuanto a los Ministros de Estado, hubo una mayor estabilidad en cuanto a los ministerios de Hacienda o sector económico que respecto de los ministerios del Interior o sector político.

Los promedios, con toda la imprecisión de ser precisamente "promedios de duración", son de 9 meses (Interior) y de 1 año 1 mes (Hacienda).

Tercero. No hay una sola razón para la estabilidad ministerial, en el caso de los tres gobiernos (18 años en total) en que se produce. Depende de diferentes características y hechos, las que se han señalado.

Tampoco hay una sola razón para la inestabilidad ministerial, en el caso de los otros cinco gobiernos del período (23 años en total). También depende de las características particulares y hechos que se consignan.

Pero hay nuevos mecanismos, distintos de la antigua censura de los gabinetes, empleados por los partidos políticos mayoritarios -de gobierno o que apoyan a éste- que buscan determinar o influir en las designaciones que, constitucionalmente, corresponde hacer al Presidente de la República.

En general, en materia de designación de los Ministros, si bien el texto constitucional fue cumplido en lo formal, puede concluirse que sustancialmente -salvo excepciones- en varias etapas no se representó cabalmente el propósito expresado en la génesis de la Constitución Política de 1925 .

Cuarto. En cuanto a la importancia política de los Ministros, ésta corresponde a la expresión de la creciente "opinión pública" que fue expresando, cada vez con mayor intensidad, sus preocupaciones orientadas hacia la atención de los problemas económico-sociales.

$\mathrm{Al}$ respecto, es de interés destacar el crecimiento de la población electoral, cuyos datos en detalle se han señalado y analizado. Basta indicar que en 1925, el porcentaje de votantes en relación a la población era el $7,42 \%$ y en 1973 era el $45,73 \%$, aumentando -entre 1925 y $1973-$ en cuanto 
un $1.390 \%$, en tanto que la población aumentó en un $142 \%$ en el mismo período. También deben destacarse los antecedentes y curso de las distintas elecciones presidenciales del período.

Todo lo anterior es determinante del crecimiento de la importancia del Ministro de Hacienda o del sector económico, y la declinación de la correspondiente al Ministro del Interior o del sector político, afirmación que se respalda con los datos proporcionados, y que es demostrativa de la señal de esperanza de la mayoría de las personas en cuanto a la atención de los problemas económico-sociales. Cuestión que estimamos unida al tema de la falta de comprensión, por la generalidad de los hombres públicos, de estas materias, que son de vital importancia para las personas, generándose así una creciente crítica hacia la actuación de las colectividades políticas y sus representantes*.

*Este trabajo es parte de un proyecto de investigación financiado por Fondecyt. 